UC.34c

Reporting Date: December 197 Issued: May 1976

\title{
LA-6194-MS
}

\section{A Set of Thermal Neution-Scattering Experiments for the Weapons Neutron Research Facility}

by

Rspert M. Brugger*

- Visiting staff member to Group P.11. Research Reactor Facility, University of Missouri, Research Park, Columbia, MO 65201.

\section{lamos}

seremestio laboratory

of the Universify of California

los ALAMOS, NEW MEXICO $8754 \mathrm{~s}$

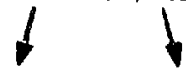

An Aftis mative Action / Equal Opporlunity Employer 
Printed in the United States of America. Availpble from National Technical Information Service

U,S. Department of Commierce

S285 Port Royal Road

Springficld, VA 22161

Price: Printed Copy \$3.30 Microfiche \$2.25

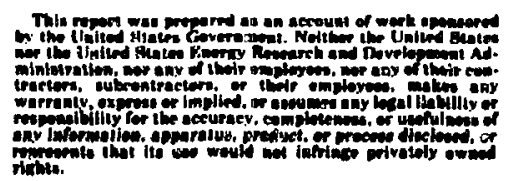

rivitu. 


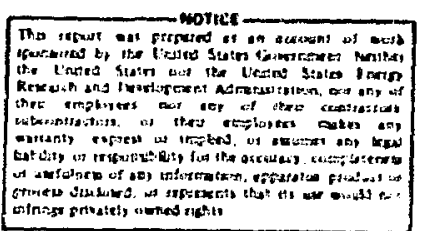

\title{
A SET OF THERMAL NEUTKON-SCATTERING EXPERIMENTS FOR THE WEAPONS NEUTRON RESEARCH FACILITY
}

by

Robert M. Brugger

\begin{abstract}
Six classes of experiments form the base of a program of thermal neutron scattering at the Weapons Neutron Hesearch (WNR) Facility. Three classes are to determine the average microscopic positions of atoms in materials and three are to determine the microscopic vibrations of these atoms. The first three classes concern (a) powder sample neutron diffraction, (b) small angle scattering, and (c) single crystal I aue diffraction. The second three concern (d) small $x$ inelastic scattering, (e) scatterigh surface phonon messurements, and (n) line widths. An instrument to couple with the WNR pulsed source is briefty outlined for each experiment.
\end{abstract}

\section{INTRODUCTION}

It is now accepted that thermal neutrons are a unique form of radiation that must be made avaibatje 10 materials scientists if they are to have a complete set of diagnostic tools. Thermal neutron scattering complements infrared, microwaves, low energy electron diffraction (LEED), Raman scattering. $x$-ray diffraction, and other physical measurement techniques. Thermal neutrons are used to detect microstructure (crystal structure, magnetic ordering, liquid shori-range orderl as well as microdynamics (dispersion relations, frequency distributions, diffusion, molecular levels). Many exampies ${ }^{1}$ now exist of the power and effectiveness of thermal neutrons. For example. Guinier2 outlined how neutrons complement $x$ rays for diffraction; $a$ recent Brookhaven National Laboratory (BNL); conference. ${ }^{3}$ emphasized neutron scattering in the biological sciences; Shiranet demoistrated how neutron scattering has elucidated the mechanisms of phase changes; and a recent meetingis of the National Science Foundation (NSF) at the Massachusetts Institute of Technology (MIT) show. ed the additions that neutrons have made in molecular spectroscopy.
As with $x$-ray diffraction and Raman scattering. the capability of thermal neutron scattering depends on the magnitude of the flux or current of radiation available. Neutron diffraction was introduced thiee decades after $x$-ray diffaction started, hence the available flux of thermal neutrons lags behind that of $x$ rays. The flux of neutrons on target runs about three orders of magnitude below $x$ rays, and this gap is widening with the step up of $x$-ray intensities by application of syncrutron radiation. Even though neutron scattering suffers from lack of flux. it is still needed because of its unique capabilities.

Figure 1 shows the increase in flux from thermal neutron sources over the years. Note that effective beam source flur of stendy state fission reactors rose rapidly in the 1940s and early 1950s, but now has reached a plateau at about $10^{15} \mathrm{n} / \mathrm{cm}^{2}$ s. Steady state sources are not expected to rise above this plateau in the foreseeable future. Note from Fig. I that charged particle reactions were the earliest sources of thermal neutrons. These reactions, when incorporating the flux magnifications of time-offlight ('TOF) techniques, have progressed steadily over the years. Because of their advantages, more intense pulsed sources are being proposed and built. 


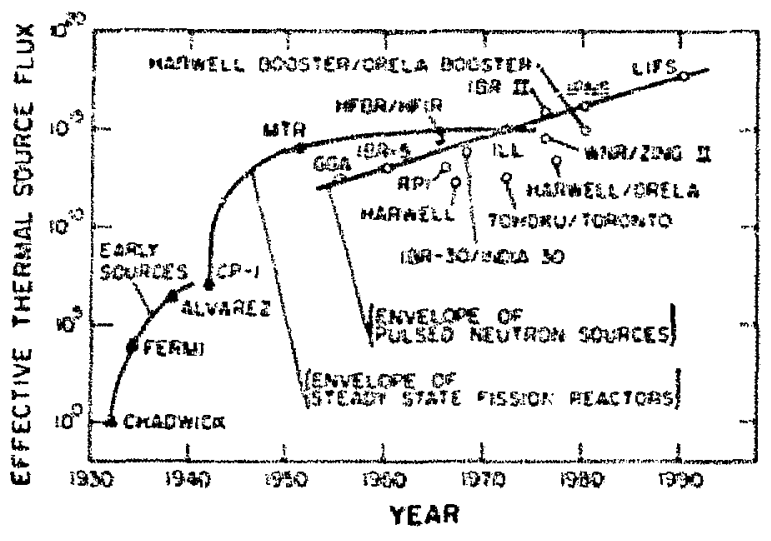

Figs.

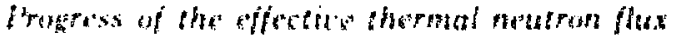

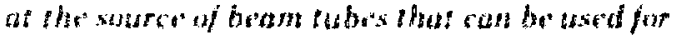

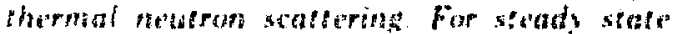
stumes this is the arerate fltax and for putsed

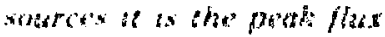

The Wafi is one of the pulsed sources currently bo. ing built.

Table 1 lists some of the pulsed neutron surtes that have been used for thetmal neutgon experinents and new stoures that are proposed ur un. der construction. Fizure 2 thows the increase in Bux that these pulsed ansurces have atrained oses the ears. Intil the newest sources under construction are in operation. the effective flux of thermat neutrons from puisted sources will las well bohind steady state fission reactors. This lag in hux is jrobably why there has been only a limited anstumt of deftnitive scientific dnta fortheoming from pulsed sources. Figures 1 and 2 demonsteate that pulsed sources promise fo reach higher effective thu levels. These gains in fux of pulsed sources and the promise of huxes above the steady state sensetion explain the ronewed interest ${ }^{6 . *}$ : in pirlsed sources.

Figure 3 shows the relative epithermal nux preduced by several tissim reactors and pulsed neutron sources. Fission peactors thave not been very effective in conducting experiments with epithermal neutgons. However, hot sources at steady state seactoss. particularly at the Institut Leve-langevin rill.h. have iacreased fux to a level where experiments are now feasible using epithermal neutrons. Pulgad fission reactors hove been omitted from Fig. 3 because their lonf pulses tender them ineffective at epithermal enerpies. For stendy state reactors, epithermal flux is low compared to thermal hux. whereas for pulsed neutron sources, epithermal thux is relatively hish comparen to thermal fiux. Thus, pulsed sources have much greater protential at

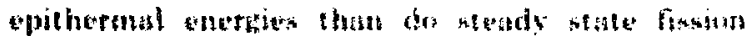

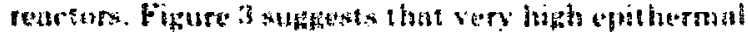

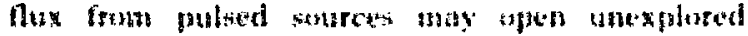
regand frot investigation. Pulsed sturess. like the

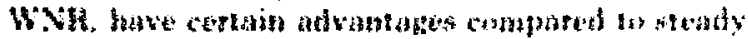

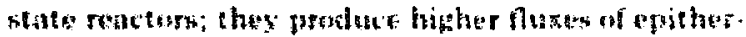

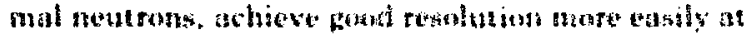

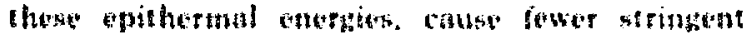
sately and licensing conditisns, and louse bower

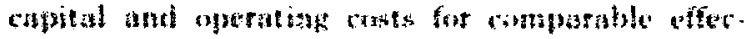
tiversess.

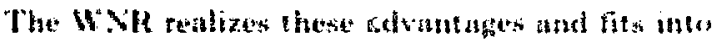

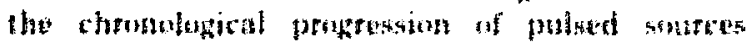

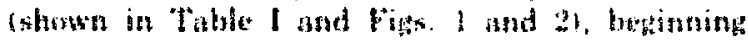

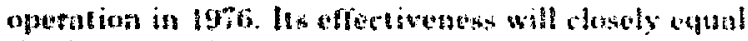

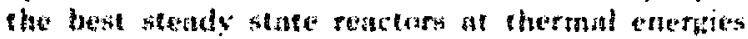
and it will be up a tatot of 5 from frevimus uperating

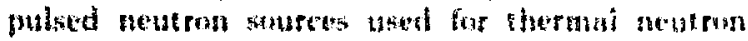
scatering. The WXR will be the first fully operational source of the new class of resy high energer, high cartent, farofon-indured newtron suntess. It can movide expertence in shimbling design, beam tabe lasoul. sumese handian.

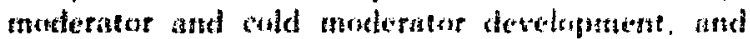

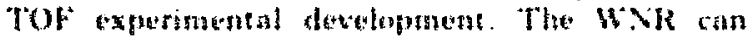

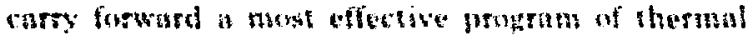

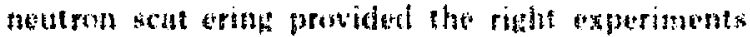
and instrumem elesign are ingtiated.

The following soctions proprest sis rlassets of ex. periments and sepromental equigment the the author dewas most effective and fonsilale. Excusted is the type of experiment wher: one can 4 ee a predicted offect with neterons, but in which the data

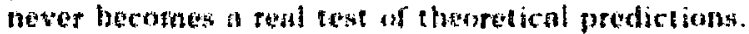
Alsw encluded are uststanding basic seicnes experiments whict. although they demongtrate an un. que property af mater. do not leat $l a$ a set of diagnoses or applications. Classes of experiments have been selected which are jutiged to be, or hecome, set of definitive methatements challenting theorists to improse their calchational metherds and pestentials for firce foldst or thay have heen selorted in lead to applied instruments and methods.

In the following aections. instrumertes for each clase of experiments ape outlined; tine constraints prevent alaburation in this report. Far the in. strumernts. TOF methods and resmonnents have been emplowed wherever possible. "Tof methods fimit orders and spurious scatterisas. and are effective for mubtidetetor. low antular resolution ex. periments and for absolute intensify measurements. As the WNR is a mulsed system. its experimental strength depends on efficient use of TOF methods.

Of the six ciasses of experiments, three are static of structure determinations and three are dynamic of inelastic scattering experiments tsee Table II). 


\section{SOME PULSED NEUTRON SOURCES USED FOR THERMAL NEUTRON-SCATTERING EXPERIMENTS}

\begin{tabular}{|c|c|c|c|c|c|}
\hline Satret & $\begin{array}{l}\text { Tous of } \\
\text { sringesten }\end{array}$ & $\Delta x=$ & $\begin{array}{l}\text { Pever nit } \\
\text { insects }\end{array}$ & 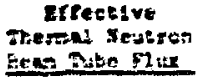 & Agerre \\
\hline $40 \mathrm{~A}$ & $2955-1965$ & Eduetros aktee & $9 \mathrm{kt}$ & $5 \times 10^{12}$ & 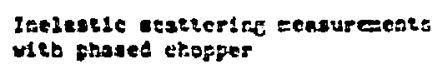 \\
\hline 10R-\$ & $1960-2969$ & rupges reactor & $s x$ & $1.6 \times 10^{13}$ & vary cost verles extericen:s \\
\hline P\$2 & $2963-2960$ & Elestran 2lest & $25 \times 15$ & $2.5 \times 10^{13}$ & 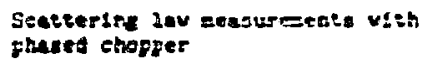 \\
\hline $\begin{array}{l}\text { O1d bervell } \\
\text { Lides }\end{array}$ & $8967-$ & Eletrest Late & 5 th & $5 \times 10^{12}$ & Dufsraetion gongurcent: \\
\hline $2 x+10$ & $1969-2972$ & $\begin{array}{l}\text { pupen reastar } \\
\text { und eccederetor }\end{array}$ & $30 \times 18$ & $1=10^{16}$ & Mary ats varled experiserts \\
\hline Fotols: & 197: - & Weetros thes & $20 \mathrm{~ms}$ & $2=10^{9.3}$ & Deffrettion \\
\hline Torosto & $2972 *$ & Eectron IItos & $20 \mathrm{x}$ & $2 \times 10^{23}$ & Poterses cryels opectroseter \\
\hline $2041-32$ & $\operatorname{lnt2}=$ & Tusent rastsin & $39 \mathrm{ht}$ & $1210^{14}$ & \\
\hline $23 x-2$ & $2972-3975$ & 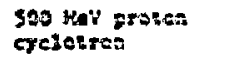 & $\cdots$ & $2=10^{12}$ & 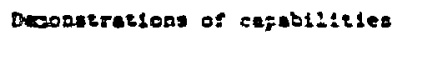 \\
\hline wath & 1976 . & 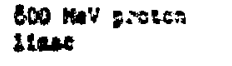 & $\cdots$ & $5=20^{20}$ & Mectes cospleston \\
\hline 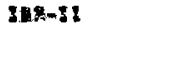 & $2976-$ & $\begin{array}{l}\text { Punes rebsut } \\
\text { and ecsoletator }\end{array}$ & $2000 \mathrm{xW}$ & $2.3=10^{20}$ & Des-10s competion \\
\hline $2 \times 0-31$ & $1976-2980$ & 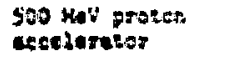 & $\cdots$ & $5=10^{78}$ & Lab eupported \\
\hline 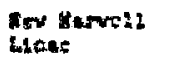 & 1978. & Elatiron diske & $62-70 \mathrm{ks}$ & $5: 20^{23}$ & nugded \\
\hline 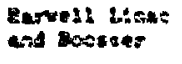 & $2950-$ & $\begin{array}{l}244 \text { toenes } 50 \\
\text { chv Sinvel } 2 \operatorname{mas}\end{array}$ & $\cdots$ & $1.5 \times 10^{15}$ & $\cdots$ \\
\hline ONow & $1978-$ & Asetros lise & $90 \mathrm{WH}$ & $5 \times 10^{23}$ & 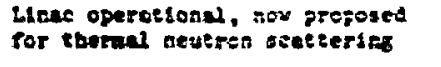 \\
\hline $\begin{array}{l}\text { abeve ast } \\
\text { 2anes }\end{array}$ & 1980 & $\begin{array}{l}\text { Ats beouter to } \\
\text { olute }\end{array}$ & $\cdots$ & $1.5 \times 10^{25}$ & Propouts \\
\hline 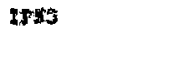 & $2960-$ & $\begin{array}{l}\text { 6xo Med frotos } \\
\text { ecenterwes }\end{array}$ & $\cdots$ & $2 \times 10^{16}$ & Proposed \\
\hline $2 m$ & $1990-$ & $\begin{array}{l}\text { Later lopicted } \\
\text { punion genctop }\end{array}$ & $\cdots$ & $1 \times 10^{20}$ & Fensble if deer rusion susceeds \\
\hline Fataten & $1950-$ & $\begin{array}{l}\text { Legar teplodire } \\
\text { romater poctors }\end{array}$ & $\cdots$ & $1=10^{20}$ & 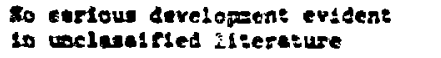 \\
\hline
\end{tabular}

Each clas is described, an experimental layout propesed. special features outlined. experimental progress inentioned, and subsets of experiments describes.

\section{I1. NEUTRON DIFFRACTION}

Neutron diffraction is the determination of the periodic atomic character of a material by measur. ing the preierential elestic scattering of neutsons from this periodic cheracter. This scattering obeys the Bragg relation

$\lambda=2 \phi_{1, k\}} \sin \theta$ where $A$ is the wavelength of the neutrons, $d_{\text {hyl }}$ is the distance between planes indexed hkl, and $\theta$ is onehalf the scattering angle. From this, cne can determine the lattice of crystais or short-range order of liquids.

Intensity of the Bragg scattering peaks is

$$
h_{h k:} \propto e^{-2 w}\left|\sum_{\rho} b_{\rho} \exp \right| 2 \pi i\left(h x / z_{0}+k y / b_{0}+\mid z / c_{0}\right)||^{2}
$$

where $h_{k 1}$ is the intensity of scattering for the Bragg peak with hkl as its index, $b$ is the scattering length of the p'th atom in the unit cell, and $e^{-2 w}$ is the Debye-Waller factor. By meesuring the intensities, 


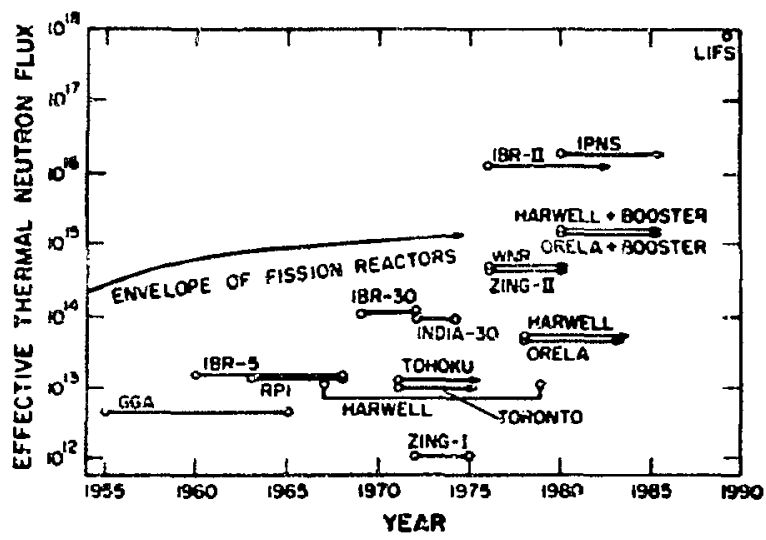

Fig. 2 .

Progress: of effective thermal neutron flux at the source of beam tubes that can be used for thermal neutron scattering from pulsed neutron sources.

one can locate the atoms in the unit cell. One can also determine the Debye. Waller factor and thus the average oscillation of the atoms about their central location. To know the lattice, space group, and Debye-Waller factor, is to know all about the average positions of the atoms in a crystal. Knowledge of crystal structure is basic to our understanding of crystalline materials. Thus, measuring this property is related to materials studies. $X$. ray and neutron diffrac:. on have had g! eat success in identifying crystal structures, both for single crystal

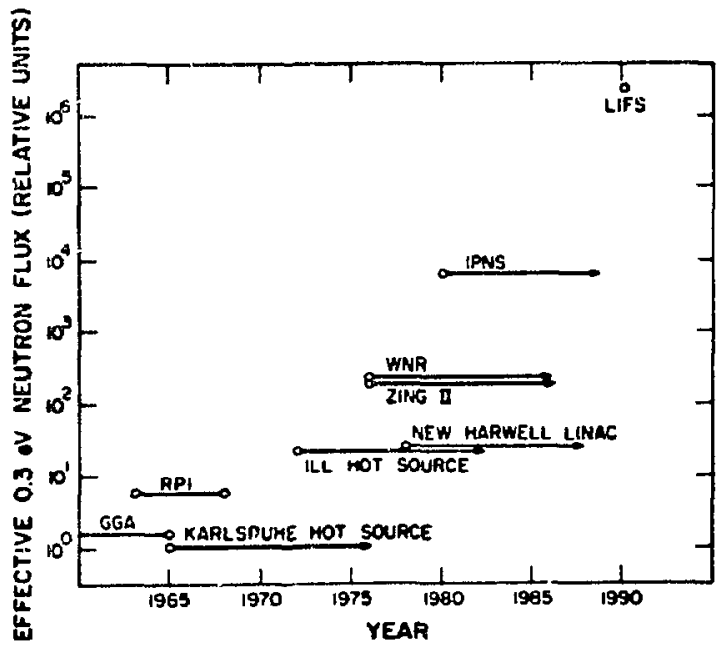

Fig. 3.

Progress of effectice epithermal neutron flux at the source of beam tubes from several neutron sources.
TABLE II

PROPOSED CLASSES OF THERMAL NEUTRON-SCATTERING EXPERIMENTS FOR WNR

\section{Neutron Diffraction \\ Powder samples \\ Small angle scattering \\ Single crystal Laué \\ Inelastic Scattering}

Small a scattering

Phonon measurement of scattering surface

line widths

samples and for powders. There seems to be no limit to the use of $x$-ray and neutron diffraction, hence three different classes of experiments for WNR are proposed to measure the structure of materiais by neutron diffraction.

\section{NEUTRON DIFFRACTION: POWDERED SAMPLES}

\section{A. Description}

In a neutron diffraction experiment. if the sample is a powder rather than a single crystal, information about the distance between the planes is measured: however, the angle between planes is not directly measured in the experiment. Quite often astute guessing can overcome this lack of knowledge of the angle. In other experiments, the lattice has already been measured; now the object is to determine the space group from the intensities of the Bragg peaks. Powder diffraction is a powerful tool for simple crystal structures, for observing the change in peak intensities as a function of a physical parameter, or for when single crystals cannot be obtained.

In conventional diffraction, $\lambda$ is fixed and $\|$ is varied to determine the d's of the Bragg equation. But when pulsed neutrons are available, " can be held fixed and the $\lambda$ 's of those neutrons which are preferentially scattered from a white spectra can be used to determine the t's and intensities.

\section{B. Experimental Equipment}

Figure 4 shows a hypothetical diagram of the TOF powder diffraction instrument. Neutrons are produced in the source and moderated by the 


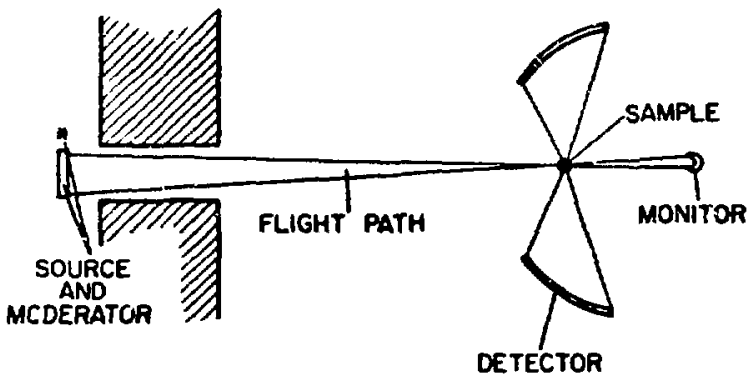

Fig. 4.

TOF pouder sample, neutron diffraction instruinent for WNR.

moderator. Some of the neutrons from the moderator pass down the flight path, scatter from the sample, and are detected by the counters. The source and moderator are arranged so that the sample does not see the scurce with its $\gamma$ flash but does see the flux of neutrons from the moderator. For the flight path, the angle of divergence is small enough and the length long enough to obtain high resolution, $\mathrm{Jd} / \mathrm{d}$. One large area detector receives neutrons scattered at different angles; the detector is positioned so that the neutrons scattered from one set of crystalline planes all arrive at the same time. The detector can also cover a large part of the Debye-Sherrer cone in the $\phi$ angle. This large-area, clam-shell detector greatly increases the counting rate. A monitor is placed behind the sample to measure incident flux distribution. The flight path in front of the sample should be evacuaied.

\section{Special Feutures}

To achieve very good $d$ resolution ${ }^{B}$ and intensity statistics, efficient detection will be needed. This is provided by large area detectors which can be multiwire proportional counters with ${ }^{3} \mathrm{He}$ gas in a common envelope. Besides covering a large part of angle $"$. they should cover $s$ much of angle $\phi$ as is practica!. Because burst width is proportional to TOF, good time resolution-and thus d resolution-are achieved at smali as well as iarge d"s. This characteristic of the pulsed source should be made use of to measure Bragg peaks with indexes as large as possible. Data in the unresolved region should also be preserved because newly developed computerized fitting methods 9 of the resolved and unresolved regions can provide a powerful means $f_{1, r}$ nistaining precise space groups. Measuring the' scattered and unscattered flux simultaneously provides more precision because both observe identical volumes of the sample.

\section{Previous Experience}

The TOF method of powder neutron diffraction has been shown to be very effective. However, the full potential of powder neutron diffraction has not been fully appreciated or realized to date, perhaps because many experimenters use conventional variable $"$ spectromeiers that do not easily go to small d's or achieve high resolution. Moreover, many experimenters are familiar with $\mathrm{x}$-ray diffraction in which the electronic structure $f^{2}$ rapidly suppresses the higher-order peaks. They have yet to reorient their thinking to make use of the good resolution and large scattering vector $\kappa$ available to neutron diffraction using pulsed source TOF.

\section{E. Subsets of Powder Diffraction Experiments}

1. Pliygical Properties of Ordinary Crystals. In many experiments the investigator follows the physical phenomena of interest by tracking crystal structure changes. The TOF diffraction instrument shown in Fig. 4 will alluw rapid tracking of these properties on relatively simple sainples $(<25$ atoms per unit cell). A complete and accurate pattern might be obtained in 1 to $30 \mathrm{~min}$. At this specd many parameter steps or sample charges will be possible.

2. Samples Under High Pressures. TOF diffrac tion is weli adapted to studying samples under high pressure. ${ }^{10}$ For these sample cells, the neutron is a more penetrating probe than $x$ rays. In addition, for TOF diffraction, eritrance and exit ports need be cut at only a few angles. These ports do not compromise the strength of the binding rings as much as when a band has to be cut to allow $\theta$ scans. $\mathrm{Al}_{2} \mathrm{O}_{3}$ has excellert high pressure qualities for cells and anvils while having low neutron attenuation. At the Materials Testing Reactor (MTR) in Idaho it was shown that the straight piston system could go to $\mathbf{4 0}$ kbar and a Bridgman anvil to 85 kbar, still allow. ing good diffraction patterns to be obtained. Detectors with an area less than that indicated in Fig. 4 will be used; nevertheless, poorer resolution can be tolerated.

3. Samples at High Temperatare. Roult ${ }^{11}$ has demonstrated that TOF powder neutron diffraction had advantages for studying samples at high temperature. $\therefore$ Recaise the samples are at extreme 
conditions, and may change or drift during measurement data from diffsaction scans of the angle will vary as the detector scans from a peak at one angle to the next. This makes interpretation difficult. However TOF observes all peaks simultaneously, obtaining an averaged pattern which can be mure easily interpreted. With the high counting rates expected, data can be obtained in a shorter time, thus limiting variations.

4. Complicated Structures. The structure of samples having thousands of atoms per unit cell is presently determined by $x$-ray diffraction from single crystals. This requires measurement of tens of thousands of reflections. To take advantage of the space selection, single crystals are used to separate peaks that may be closely spaced in plane spacing distance. For $x$ rays, the peaks must be observed at smaller $d$ 's before $? 2$ reduces the intensity beyond the point of detection.

With the new capabilities introdured by pulsed neutron sources, it should be possible to push the complexity of powdered samples stuitied to many more atoms per unit cell than has been achieved by neutrons in the past. 13,14 With increased epithermal flux, high plane spacing resolution will allow observation of many more reflections at larger indexes. In formation can be extracted from the unresolved region by the raw data fitting methods presently used. Because neutron diffraction does not attenuate by the electronic structure factor $\mathrm{f}^{2}$. Bragg peaks at large d's will still be observable.

Figure 5 is an example of recent measurements of $\mathrm{Pr}_{-} \mathrm{O}_{12}$ made by Yarnell15 using a good resolution. variable-angle sfectrometer at the Los Alamos

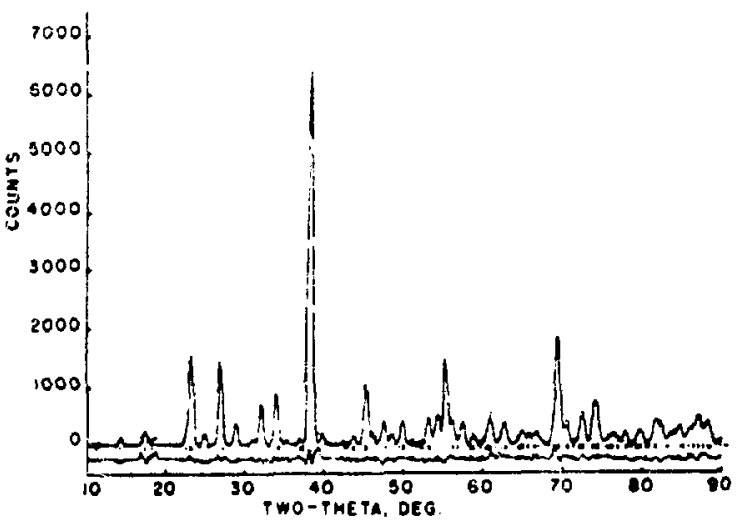

Fig. 5.

A pouder sample diffraction pattern of $\mathrm{P}_{7} \mathrm{O}_{l}$ taken with a good resolution conventional neutron diffraction instrument at the steady state (Imega West reactor. The ladder of hash marks indicates positions of expected peaks.
Scientific Laboratory (LASL) Omega West Reactor. Both the powder pattern and the ladder of expected peaks are shown. Even though the diffraction pattern does not resolve all the peaks, the pattern is interpreted by tha data fitting method. With a TOF spectrometer of higher resolution, the pattern in this region can be resolved and an additional area of un. resolved peaks containing information will be available.

5. Diffraction with Polariced Beams. The ability to distinguish polarization of scattered neutrons would add a powerful diagnostic and filtering capability. ${ }^{16}$ With an effective polarizer (such as $\mathrm{MgLaNO}_{3}\left(\mathrm{H}_{2} \mathrm{O}\right)$, crystals) the TOF diffractometer can adapt well to such modifications. A polarizer placed in the flight path of the incident beam defines the polarization of the incident neutrons and a polarizer placed in the flight path behind the sample analyzes the polarization of the neutrons after scattering.

Neutrons scattered coherenily from hydrogen atoms preserve their spin orientation, whereas neutrons scattered incoherently from hydrogen atoms flip their spin. Coherent scattering by hydrogen atonss is a very small percentage of in. coherent scattering. It is the ability of neut:ons to locate hydrogens, even !hougn the coherent scattering is small, that is one of the unique capabilities of neutron diffraction. Tiu coherent signal as com. pared to the incoherent background of scattering from hydrogen wouid bi greatly enhanced by using polurized beams and analysis to ouserve only the scattering that occurs with no change of polarization.

6. Electron Density Maps. Neutron diffraction locates the positions of the nuclei of atoms in crystals whereas $x$-ray diffraction maps the distribu. tion of the electron density. Careful measurements of both followed by subtraction of nuclear from elec. tron density leaves a map of the nonnuclear centered distribution of the electron distribution. These maps are important for showing the distribution of the valence electrons.

\section{Conclusion}

The TOF neutron diffraction experiment, using powder samples, provides access to a whole set of experiments that will produce definitive data. It takes advantage of the strong capabilities of pulsed sources, such as thic use of epithermal neutrone, the use of large area detectors-to obtain high couning rates, and the adaptability to special sample cells. 
IV. NEUTRON DIFFRACTION：SMALL ANGLE SCATTERING

\section{A. Description}

Some of the periodic characteristics of materials have repeat distances that are very large. This is particularly significant for biological materials, polymers, and radiation damage centers. ${ }^{17-26}$ To reach these large d's (10-1000 A), the Bragg relation $\lambda=2 d \sin "$ shows that large $\lambda$ 's $(\sim 5-10 A)$ and very small ${ }^{\prime}$ 's $\left(<10^{\circ}\right)$ are required. To reach these conditions requires special experimental instruments.

\section{B. Experimental Equipment}

Figure 6 shows a hypothetical diagram of a small angle scattering instrument for WNR. Neutrors are produed by the source and moderated in the moderator. Some fly down the flight path, scatter from the sample, and are caught by the detector. It is asstimed that all scattering is elastic; inelastic scattering is small enough to be ignored. At small angles, the concept of putting the detectors on the surface of constant TOF for each d cannot be used because that surface is now at glancing angle. A detector sensitive to both space and time (hereafter called an S-T detector) is employed. Part of the S-T detector is a computer which identifies the location and time of each captured neurro and converts this $S-T$ information into $d$ by the $B r a_{\imath} ; g$ relation. Then the number of captures or events per $d$ is stored in the computer.

Tris system int egrates the events corresponding to equal $d$ spacings that had larger $\lambda$ and $\theta$ with those for $\cdot$. valler $\lambda$ and $\|$. The flux decreases as $\lambda$ inczeases, although the scattering decreases as $\theta$ increases. therefore this integration will tend to equalize the number of events over the range of d's and improve the statistical accuracy.

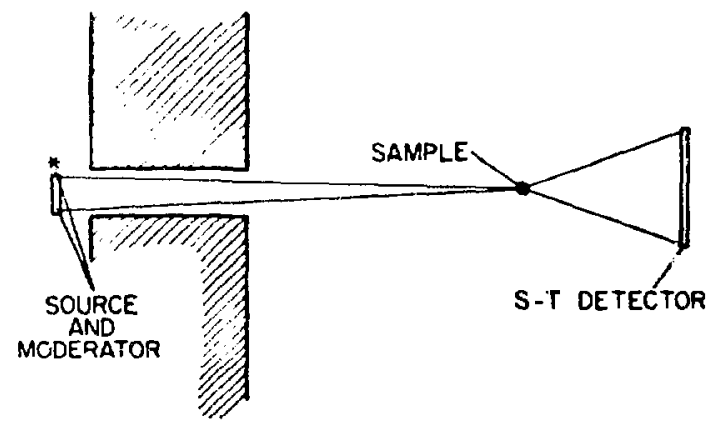

Fig. 6 .

A small angle diffraction instrument for WNR.

\section{Special Features}

Integration of data taken at different $\lambda$ 's and $\theta$ 's but for the same d's is one feature of the small angle spectrometer. Integration significantly increases the counting rate of the experiment. The flight paths will be evacuated to limit air scattering. It is important to develop and use an S-T detector so that date from many scattering angles and for many incident wavelengths can be obtained simultaneously.

\section{Previous Experience}

Small angle scattering with neutrons has been long in coming; however, much physical data is now being obtained since its initiation at Jülich and perfection at Grenoble. Flux requirements are modest enough, however, to permit good performance in intermediate flux reactors. Small angle scattering has not been tried by true TOF; velocity selectors have only been used to select one incident wave length. The experiment proposed here is a true TOF experiment.

\section{E. Subsets of Experiments}

1. Samples in Special Environments. The proposed instrument, in addition to measuring the long range uder of bioiogical samples and polymers, can measure small angle scattering from samples under extreme conditions. These latter samples can either be under high pressure or at high temperature.

2. Radiation Damage. Small angle scattering can detect the size and shape of damage centers. If the sample is oriented (a single crystal), the damage centers may be oriented and the diffraction will define their size and shape. It should be possible to construct shielded casks with small entrance and exit ports so that scattering can be seen from extremely radioactive samples.

3. Magnetic Scattering. With a polarizer in front of the sample and a polarized sample, specific long range magnetic properties might be observed.

\section{F. Specific Instrument}

Figure 7 shows a small angle scattering inst rument which is used to evaluate magnitudes of the components to be built. is guide tube or collimator of a cross sectional area $0.5 \mathrm{~cm}$ by $0.5 \mathrm{~cm}$ and $10-\mathrm{m}$ iong 


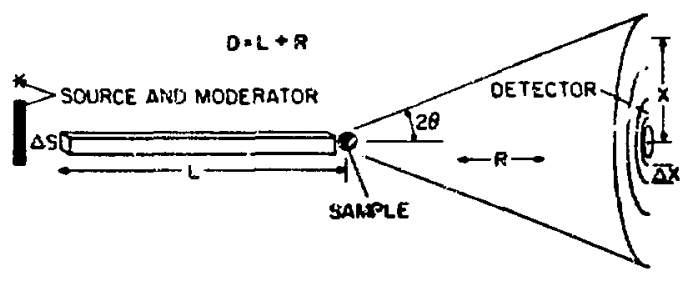

Fig. 7 .

Small angle diffraition instrument.

defines the beam from the moderator to the sample. The divergence of this tube is $\delta i=0.5 / 1000$ $=5 \times 10^{-4}$. Neutrons interact with the sample and some are scattered through small angles $X / R$.

An S.T detector is placed at distance $R=10 \mathrm{~m}$. Counts from the detector are sorted into bins of constant $d$. Thus more of the total spectra is used, since counts from large angles and large $\lambda$ are added to those of small angle and small $\lambda$. The computer program should accept only a band of $\lambda$ to limit the spread in resolution (see Fig. 8). Thus the computer acts like a band pass filter.

It is desirable to achieve constant plane spacing resolution

$\frac{\Delta d}{d}=$ constant $=\left[\left(\frac{\Delta X}{R}\right)^{2}+\left(\frac{\Delta S}{L}\right)^{2}+\left(\frac{\Delta T O F}{\text { TOF }}\right)^{2}\right]^{1 / 2}$

with each term contributing about the same magnitude. Resolution from the burst spread

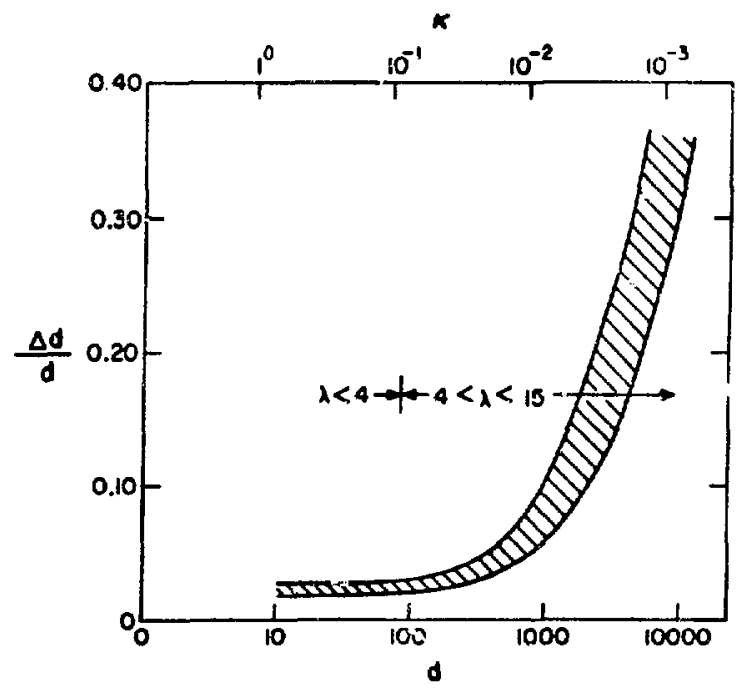

Fig. 8 .

Expected resolution from the diffractometer shown in Fig. 7. $\triangle T O F / T O F$ will be nearly constant because for long times-of-flight

$\triangle \mathrm{TOF}=$ constant $\mathrm{TOFY}$

where $Y$ is 1.0 for thin moderators increasing to 1.6 for thick moderators.

Detector width resolution $\mathrm{AX} / \mathrm{K}$ can be made constant by computer sorting in $X$ bins when the width of each bin $X$ is proportional to $\Delta X$.

$\Delta \mathrm{X}=$ const $\cdot \mathrm{X}$.

It is not evident that the resolution associated with incident beam divergence $\triangle \mathbf{S} /$, can be made constant and that this will broaden the resolution at large $d$. Figure 8 plots estimates of $\mathrm{Jd} / \mathrm{d}$ for ti.e layout shown in Fig. $T$ assuming $\triangle \mathrm{TOF}=(1 / 50)$ TOF. This gives a 300$) \mu \mathrm{s}$ burst at $\lambda=3 \AA$. The $\mathrm{S}-\mathrm{T}$ detector is $\sim 1 \mathrm{~m}$ edge to edge. which seems reasonable. Its minimum resolution $\mathbf{A} \mathrm{X}_{\mathrm{rmm}}$ might be $2 \mathrm{~mm}$.

\section{G. Conclusion}

A small angle scattering instrument at WNR can open up a whole class of significant experiments on the mateial properties of biological molecules, polymers, and radiation damage. TCF methods adapt well to these measurements.

\section{NEUTRON DIFFRACTION: SINGLE CRY * STAL LAUE}

\section{A. Description}

In the Laue method of diffraction, a white beam of radiation strikes a single crystal; the radiation that is Bragg scattered by many planes is observed as spots on a space-sensitive detectur. The strength of this method is the direct measurement of the angle between planes, which is a great help in determining the lattice. Its weakness is that the intensity of each spot contains several orders of scattering; thus the intensities of each $d_{h k !}$ are not reliably determined. Mortover, for $x$ rays, the flux distribution of the white beam of $x$ rays is not well known. TOF Laue neutron diffraction can overcome these weaknesses. In place of the space-defining detector. an S-T sensitive detector will be used. TOF will sort the orders in each spot, while a beam monitor precisely measures the flux spectra of the white beam of neutrons. 


\section{B. Exparimental Equipment}

Figure 9 shows a hypothetical diagram of a TOF Laue diffractompter for WNR. Neutrons made in the source and moderated by the moderator fly down the night poth, scatter from the single crystal sample. and are detected by the S.T detector. The instrument need not have extremely good space or time resolution but should have high counting rates to whtain good intensity statistical resolution.

\section{Specia! Features}

TOF modificetion of the Laue method can sort the multiple orders in each peak which make it a complete and very powerful diffraction instrument. Its high counting rates allow use of small samples which in turn reduce self absorption. Its use of all neutrons and favorable thermal neutron-ti-gamma tatio reduces exposure time, thereby reducing radiation deterioration of the sample.

\section{Previuus Experiences}

In x-ray haue diffraction, no space detector is presently available that can also distinguish $x$-ray energies. Thus, order separation in the r-ray measurements is not possible. For neutrons, the TOF Lnue method has been shown to work but it has not been adapted for extensive use because no S.T detector has been availahle. Nunes ${ }^{27}$ tried using a correlation chopper $t_{3}$ distinguish order with limited success. Building an $S-T$ detector for neutron diffraction appears within the state of the sit.

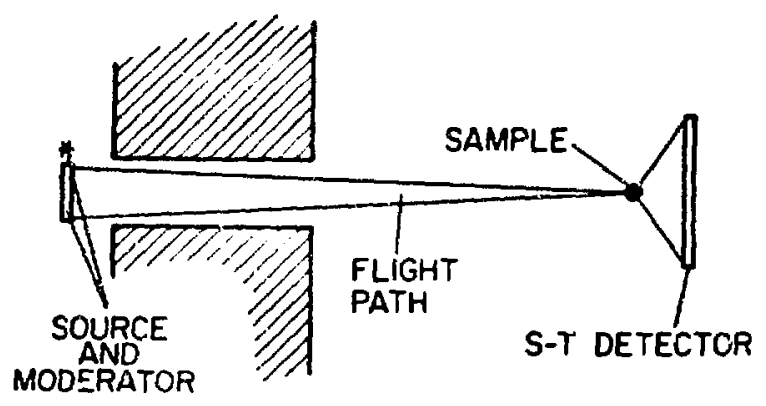

Fia. 9

A TUF Laue diffraction instrument for use on WNR

\section{E. Subsets of Experiments}

1. Ordinary and Complex Samples. With the single crystal Laué instrument, ordinary crystals can i)e run quiskly and with complete data. The instrument has the rate capability to tackle the most com. plex samples.

2. Polarized Scattering. By adding polarizeò filters to the Laue spectrometer, one can select coherent scattering and filter out incoherent scatte: ing by the preservation-of -polarization principle. This may allow detection of very weak peaks which arise from hydrogen scattering from a much greater incoherent background.

3. Phase Determinations. X-ray and neutron diffraction megsurements of Bragg peaks give the syuare of the scattering effect. The phase relation. which is treeded for a unique determination of the atomic positions within the urit cell, 28 is lost by measuring the square. In the past, astute guessing has been used, but as the crystals become more complex direct methods are needed.

Neutron scattering from a few isotopes is accompanied by lurge absorption. This absorption adds an imaginary pari to the scattering length and produces anomalous scattering which containe information about the phase. By measuring the scattering above and below the resonance, seattering length and ad. ditional phase infor nation can be obtuined.

In addition to anomalous scattering, there is also Schwinger scattering 29 (intarference between nuelear and electronic potential) which produces a right-and left-handedness to some scattering. This also may be used to determine phase. With the TOF Laue method, it should be possible to take advantage of anomalous and Schwinger scattering. The TOF method will measure at different $\lambda$ 's, so.ne above the resonance energy and some below. This may provide the means for extracting the phase.

4. Samples Under High Pressure. It should be possible to use the Laue diffractometer to observe the crystal structure of sampies under very high pressure. Figure 10 shows a sample cell which shouid be able to hold a sample at $100 \mathrm{kbar}$. A similar pressure system was built and tested at MTR. The igure shows \& Bridgeman anvil design with $\mathrm{Al}_{2} \mathrm{O}_{3}$ anvils in which the incident beam and scattered beams enter and leave along the anvil axis. 


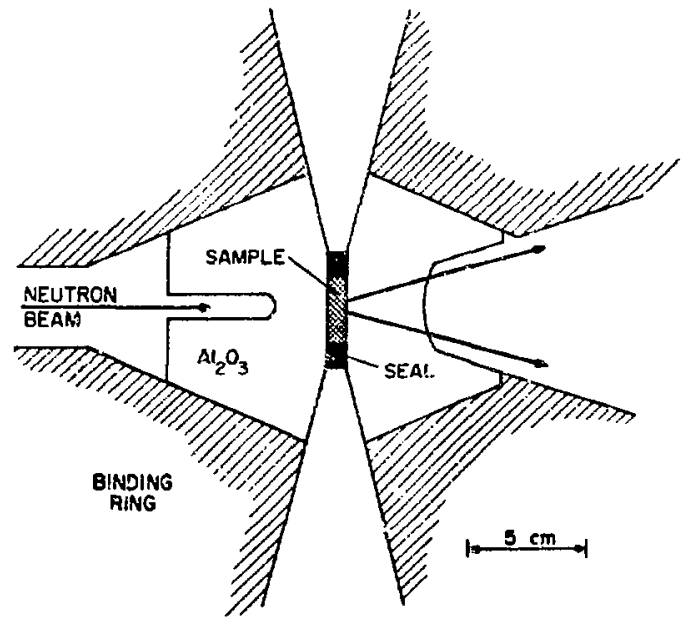

Fig. 10.

High pressure region of a Bridgeman anvil press that could be used for TOF Laué patterns.

\section{E. Conclusion}

The TOF Laué method appears particularly well suited to measure neutron diffraction patterns from single crystals with a pulsed neutron source. This will compete favorably with the full circle method of steady state reactors.

\section{INELASTIC SCATTERING}

Turn now from microstructure measurements to microdynamic measurements. Inelastic neutron scattering is the excitation or deexcitation of molecular quantum states in a material when a neutron scatters from the material. In these cases, the neutron loses or gains energy upon scattering; measurement of this loss or gain detects the quantum states of the material. If the scattering is coherent as well as inelastic, measurements record information about direction of the wave or location of the vibration in microscopic zones of the material. When the number of vibrations is recorded, a function related to the frequency distribution--the frequency spectra-is also recorded.

One of the unique powers of neutron inelastic scattering is that the neutron has the proper range of relations between its energy and momentum to detect the coupled relation between the energy and momentum of waves in the material. Electromagnetic radiation does not have this match and has been unable to do this so far. hinelástic scattering measures the microdynamics of a material. Data obtained from inelastic scattering places stringent requirements on the force models and potential funcions used to describe the material. Three sets of inelastic scattering experiments are proposed for WNR.

\section{INELASTIC SCAFTERING: SMAIL $K$ METHOD}

\section{A. Description}

For inelastic scattering, one wants to measure as accurately as possible the excitation of a discrete energy state of a molecule. The resolution with which the scattered neutrons can be defined is a function of the resolution of the spectrometer as well as a "recoil resolution" characteristic of the samp's and interaction parameters. The recoil resolution! is appreciabie for samples that show diffusion, such as molecular gases or liquids.

Recoil resolution is

$$
\Delta E_{\text {rec } G i l} \alpha \cdot\left(\frac{K^{2} T}{M_{\text {eff }}}\right)^{1 / 2}
$$

where $J \mathrm{E}_{\text {tecil }}$ is the recoil resolution, $\kappa$ is the wave vector of scattering, $T$ is the temperature of the sample. and $M_{\text {eff }}$ is an effective mass of the sample molecules. To improve recoil resolution one reduces the temperature and $\kappa$ or increases effective mass. However, lowering temperature or increasing effective mass ustally takes the sample to a new phase, thus changing the experiment. To reduce $\kappa$ for any given energy exchange valiı, one must go to smaller scattering angles and higher incident energies. Higher incident energies are in the region where a pulsed source like WNR should excel. For solids where recoil resolution should be zero, small $n$ ineasurements of molecular spectra still have an advantage; multiphonon scattering backgrounds are reduced relative to the single scattering events.

\section{B. Experimental Equipment}

Figure 11 shows a hypothetical diagram of a proposed small $k$ instrument. Neutrons from the source are moderated by the moderator and fly toward the sample. These are interrupted by a chopper phased to the source. The phase lag of th. chopper is set so that only a burst of monoenergetic neutrons is passed. This burst scatters from the sample, some neutrons exchange energy, and this energy change is measured by time of flight to the counter. 


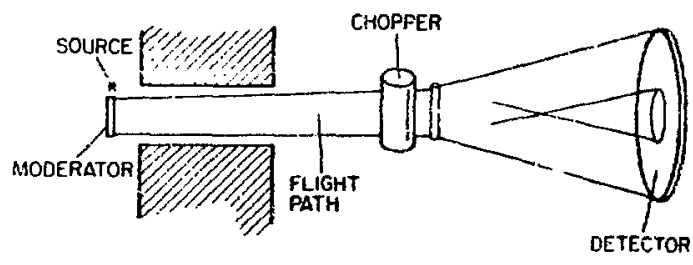

Fig. 11 ,

A small $\kappa$ inelastic scattering instrument for WNR.

\section{Special Features}

The small $\mathrm{s}$ method is designed to measure interpretable inolecular spectra data. Evacuated flight paths eliminate air scattering. Use can be made of a tall sample container and a detector which is only sensitive to time whose area can be large becasse good space resolution is not important. A chopper needs to be developed to give good timing in the $0.05-0.5 \mathrm{eV}$ range. Programs have been written to fit the data; they can be used for precise definition of energies and intensities.

\section{Experience}

The small $\kappa$ method of molecular spectroscopy, which improves resolution by taking data at small $n$ 's, was successfully conducted at the MTR. At a recent NSF meeing5 Dr. Bruce Hudson stated that the M'IR small $K$ data is the only molecular spectroscopy data so far produced by neutrons that can be interpreted both for energy exchange and intensity. The MTR measurements were on a thermal reactor, hence the upper limit of usable flux was about $0.1 \mathrm{eV}$. WNR will have high performance above 0.1 $\mathrm{eV}$ where recoil resolution can be further improved.

\section{E. Subgroups of Experiments}

1. Molecular Gases. The smail $\kappa$ method can produce definitive molecular spectroscopy data for molecules in the gas phase. 30 Modes of greatest interest are the optizally forbidden rotatiunal and vibrational modes that are inaccessible to infrured and Raman. The modes will be measured for dilute gases where intermolecular effects are negligible.

2. Molecular Liquids and Dense Gases. Similar molecular states will be measured as in the receding paragraph. In addition, a determination will be made of the intermolecular effects which were introduced by the molecules being in dense gases or liquids. In solids that still have a diffusive mode (for example, $\mathrm{NH}_{3}$ molecules that can still rotate or librace), these transitions will be resolved.

3. Solids. The small $\kappa$ method may be advantageous for measuring the frequency spectra of solids. Small $\kappa$ measurements suppress multiphonon scattering relative to single phonon spectra thus making the latter more distinguishable. They are the only way to measure $x[\vec{q}, \omega]$ for magnetic metals where the limit is always $Q \leqslant 4 \AA$, perhaps $Q \leq 2 \AA$, and it is desirable to have $\hbar \omega \geq 500 \mathrm{meV}$.

\section{F. Conclusion}

The power of the small $\kappa$ method has been demonstrated. When using instruments of high resolution, its application promises to produce excellent molecular spectroscopy data.

\section{INELASTIC SCATTERING: SCATTEK- ING SURFACE METHOD}

\section{A. Description}

The "constant Q" method of measuring dispersion relations for single crystals has become very popular and has many advocates. ( $Q$ and $\kappa$ are the same.) Steady state reartors with three-axis spectrometers use this method whereby three of the four parameters of the spectrometer are adjusted so that each data point of the sample is taken at the same position in reciprocal space while the energy change is stepped through a set of energies.

A similar approach, but not quite as well aimed, can be conducted with TOF at a pulsed neutron source. Schmunk and Brugger ${ }^{31}$ at MTR showed how the scattering surface method could be used to obtain data in the desired $\vec{Q}$ direction which is near but not exactly at the desired $\overrightarrow{\mathbf{Q}}$ magnitude.

\section{B. Experimental Equipment}

Figure 12 shows a hypothetical TOF scattering surface instrument. Neutrons from the source are moderated and fly toward the sample. A chopper, phased with the source, passes bursts of monochromatic neutrons which are scattered by the single crystal sample. Some of these neutrons that scatter coherently and inelastically are detected by the seis of counters. These counters are set to detect inelastic scattering surfaces that cross a given $\vec{Q}$ 


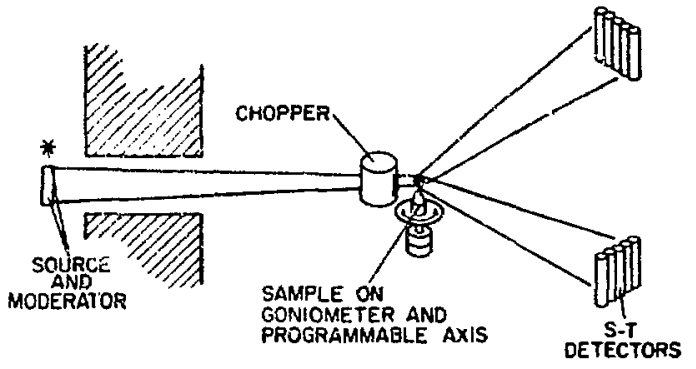

Fig. 12.

A TOF scattering surface instrument for measuring phonons in fixed directions of reciprocai space.

direction of the reciprocal lattice near the desired magnitude of $|\vec{Q}|$. If dispersion relation curves are to be traced out, the slight miss in the magnitude of $\vec{Q}$ (and this $\vec{q}$ ) will make little difference in the instrument's ability to trace the full curve. However, if the experiment calls for phonon energy at an exact $\vec{Q}$ (both direction and magnitude), 3 to 12 different runs for a set of $\mathbf{E}_{0}$ or crystal orientations will be needed to obtain data for extrapolation to the exact $\overrightarrow{\mathrm{Q}}$.

\section{Special Features}

Angular resolution needs to be good in the scattering plane but relaxed above and below it, hence sets of tubular counters can be used. Banks of counters at a number of angles can run simultaneously. The central position of each bank of counters must be adjustable and programmable in the $Q$ plane. The sample will be mounted on a programınable axis that moves when tho arm to the counter banks moves.

\section{Past Experienre}

To date, the success of the "constant Q" method which uses three-axis spectrometers with steady state reactors and the limited intensity of pulsed sources, has discouraged application of the scattering surface method.

\section{E. Subsets of Experiments}

Subsets of experiments are numerous. The scattering surface method used with pulsed sources should open up all the possibilities of inelastic nieution scattering for which the constant $Q$ method, using three-axis spectrometers with a steady state reactor, is being used.

\section{F. Conclusions}

The scattering surface method enables a TOF system to approach a three-axis spectrometer in measuring the energy of phonons at a prescribed $\vec{q}$.

\section{INELASTIC SCATTERING: LINE WIDTHS}

\section{A. Description}

Whenever motion of atoms in a material experience anharmonic forces (barrier penetration, diffusion, translations), the anharmonicity will cause discrete elastic and inelastic scattering to exhibit a broadening. ${ }^{32-36}$ For translational motions, such as atoms in a gas, the broadening is very large, dominating the scattering, and producing tens of $\mathrm{meV}$ of broadening. (It is to limit this translational broadening of the molecular vibrations of molecules in gases that the small $\kappa$ method outlined in Sec. VII was developed.) For diffusion, as in a liquid, the elastic and inelastic peaks associated with molecular vibrations are broadened by units of $\mathrm{meV}$ (the elastic peak in this case is called quasielastic). For barrier penetration (such as methyl librations in solid neopentane) the rotational levels are broadened by units of meV. For dispersion relations, inelastic scattering peaks which arise from excitation of a lattice wave may be broadened by $\mu \mathrm{eV}^{37}$ because of phase transformations or other arharmonic effects. Measurement of these broadenings may provide valuable information about the anharmonicity of the forces.

\section{B. Instruments}

1. TOF Instrument. Instruments to measure tens of $\mathrm{MeV}$ are not needed since translational motion is well understood; additional measurements are of limited interest. Instruments to measure units of $\mathrm{MeV}$ are described in Secs. VII and VIII which will suffice to measure broadening caused by diffusive motions, librations, and very anharmonic phonons. However, to reach $\mu \mathrm{eV}$ broadening, special instruments are needed.

One such special instrument is proposed in Fig. 13. Neutrons from the source are moderated to cold neutrons by the cold moderator. Bursts from WNR 


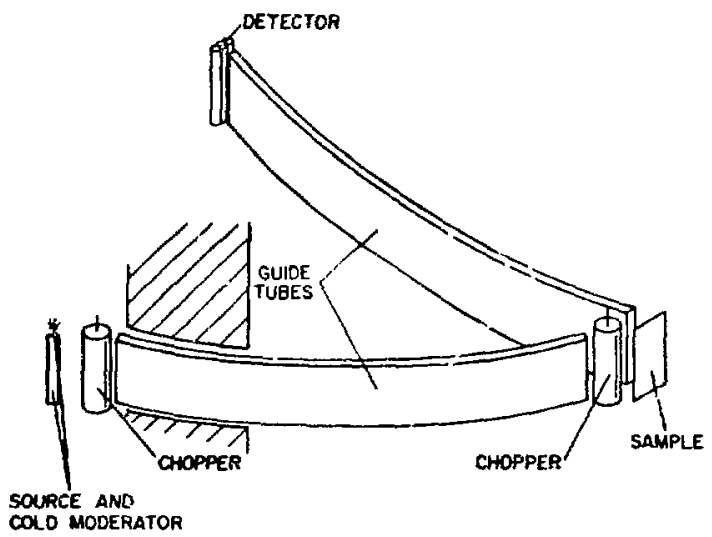

Fis. 13.

TOF instrument for line width measurements of high resolution.

will not be short enough to give the required high resolution, therefore two choppers are used as a velocity selector, one inside the target shielding and one in front of the sample. A burst of cold neutrons travels down the guide tube. The second chopper passes only those of one velocity which scatter from the sample; the gain or loss of energy is determined by measuring the TOF to the detector. Tall guide tubes are needed to accept all of the neutrons from the highest intensity part of the moderator.

For liquids or powders, one guide tube behind the sample is adequate. To measure line widths of low level phonons it would be advantageous to have a number of guide tubes and detectors for application of the scattering surface method.

2. TOF Instrument Resolution. If the choppers have burst times of $10 \mu$ s each, guide tube lengths of $10 \mathrm{~m}$ each, and $E_{0}$ and $E_{f}$ are $0.005 \mathrm{eV}(1000 \mu \mathrm{s} / \mathrm{m})$, the resolution of $\mathrm{E}_{4}$ is

$\Delta T_{0}=\left[\left(\frac{10}{10^{4}}\right)^{2}+\left(\frac{10}{10^{4}}\right)^{2}\right]^{1 / 2}=1.4 \times 10^{-3}$

$\Delta \mathrm{E}_{0}=2.8 \times 10^{-3} \mathrm{E}_{0}=14 \mu \mathrm{eV}$.

\lrcorner $E_{4}$ includes the $14 \mu \mathrm{eV}$ of $\lrcorner E_{0}$, as well as thight path uncertainties, channel widths, etc. It might be reasonable to predict a resolution of $2 \times 14 \mu \mathrm{eV}$ or $\sim 30 \mu \mathrm{eV}$ for the total instrument.
3. Diffraction Instrument. Figure 14 shows a hypothetical diagzam of a line width spectrometer for very high energy resolution measurements. Neutrons from the source are moderated by the moderator and fly toward the sample. The moderator rotates as fast as possible, say with an edge speed near $500 \mathrm{~m} / \mathrm{s}$. A 5-cm-wide moderator would exit from the beam in $100 \mathrm{~ms}$, thereby cutting off the tail of colci neutrons for burst times $>100 \mu \mathrm{s}$.

The instrument operates as follows. Moderated neutrolis fly down a 100 -m-long flight path formed by a neutron guicie and strike the sample from which neutrons are quasi-elastically scattered. The energy of the scattered neutrons is analyzed by a large area curved silicon crystal analyzer, ${ }^{38}$ which makes use of the high resolution of the back-scattering analyzer. The crystal focuses on a counter just beyond the sample. A filter removes orders and faster neutrons.

\section{Subsets of Experiments}

1. Diffusion in Liquids. An understanding is needed of the different types of motion which contribute to quasi-elastic scattering. Data for a number of ranges of $x$ provide this understanding and can yield definitive information about the mechanism of diffusive motions in liquids.

2. Molecular Librations in Liquids and Solids. The effects of liquid-like behavior are determined by measuring the width of the quasi-elastic peak at very small $k$. Then the broadening of the inelastic peaks, which is corrected for liquid-like behavior, would reveal the diffusive motion of molecular reordering and molecular librations. This motion should give some information of the anharmonicity of molecular

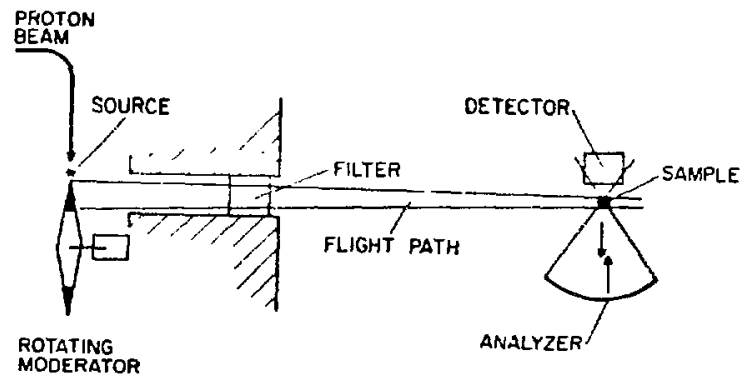

Fig. 14 .

Diffraclion analyzer for line width measurements of high resolution. 
libration potential. The same processes will hold true for the solid but without the effect of liquid diffusion.

3. Phonon Widths. In solids, near or at phase changes, the phonon peaks should show a broadening which indicates an increased tendency of the atoms to move from their crystal sites. These broadenings are in $\mu \mathrm{eV}$; their measurement should provide valuable information about the potential shapes near these phase changes.

\section{Conclusion}

The WNR could make an effective study of anharmonic potentials by measuring widths of quasielastic and phonon peaks.

\section{MODULAR SYSTEM}

Methods outlined in Secs. III-IX maximize the use of TOF methods while minimizing the use of diffraction components (crystal monochromators and anaiyzers). Many of the experiments have common components; thus interchange of modules is possible and, indeed, beneficial. Two lengths-of-flight paths will accomodate most instruments: long paths for high resolution and short for low resolution, high count rate experiments. The choppers can be modules added at the end of these flight paths, most of which will benefit from being evacuated.

\section{A. S-T Detectors}

To adopt the modular approach requires special attention to development of several modules. S-T sensitive detectors are needed to capture the full power of pulsed sources. $39 \mathrm{BNL}$ and ILI. have developed delay wire or crossed wire detectors that are space sensitive; it may be possible to make them fast enough to be time sensitive as well. A search should be made in the areas of high energy physics, nuclear medicine, and aerospace development for systems that can be modified to form a large S-T detector.

\section{B. Choppers}

The second module to develop is a chopper with timing resolution to $0.5 \mathrm{eV}$. Noncadmium materials must chop the thermal and epithermal neutions. Choppers need not be as heavy as those at steady state reactors because the average fast flux which comes down the beam tube is much lower. Design of such choppers does not seem prohibitive. Ways must also be developed of phasing these choppers to bursts from the accelerator, a trivial matter for linacs triggered by the chopper, but a questionable undertaking for the configuration at the Los Alamos Meson Physics Facility (LAMPF).

\section{INITIAL IMPLEMENTATION}

Physics Group P-11 at LASL has acquired surplus TOF equipment from MTR. The group plans to use the equipment to initiate, test, and develop the classes of experiments outlined in Secs. III-IX. Acquired were $(a)$ an evacuated flight path, (b) $\sim 12$ each $25-\mathrm{cm}$-long and $10-\mathrm{cm}-$ long ${ }^{3} \mathrm{He}$ counters, (c) several Fermi choppers, and (d) shielding for the choppers. The evacuated flight path has the following parameters: sample-to-detector distance of $2 \mathrm{~m}$, a sample shield, holders for $25 \cdot \mathrm{cm}$-long and 10 $\mathrm{cm}$-long ${ }^{3} \mathrm{He}$ courters, and a $\triangle \theta$ of $\sim 25^{\circ}$. Figure 15 shows equipment arrangements for the three classes of neution diffraction experiments.
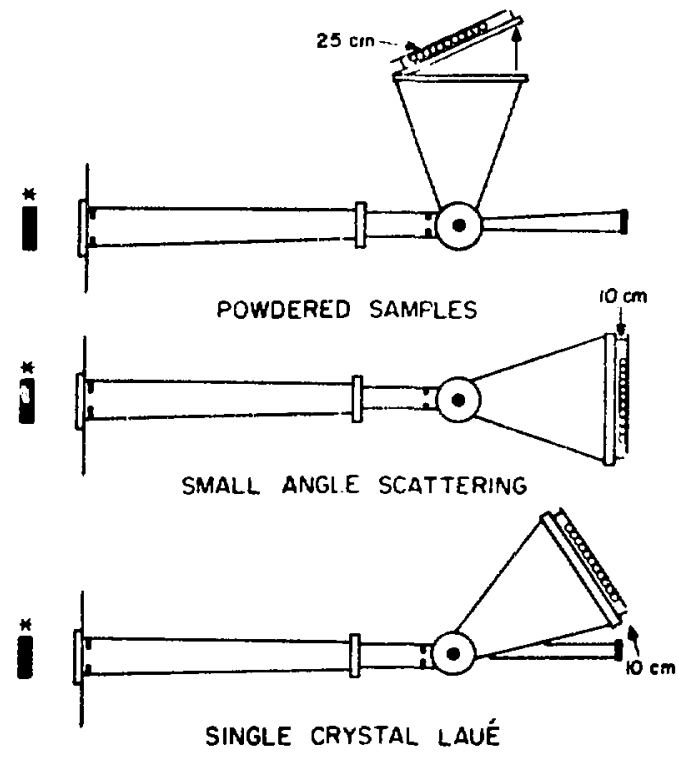

Fig. 1.5.

MTR equipment arranged for neutron diffrac. tirn measurements. Dimensions refer to the length of detectors to be used. 


\section{A. Powdered Samples}

A longer flight tube is fitted with collimators behind the moderator and in front of the sample. The MTR evacuated flight path is fixed to rotate about the sample position; it is rotated to a scattering angle of $90^{\circ}$ where the vertical counters better match the Debye-Scherrer cones. The flight tube is modified so that the counters fall on the surface of the same TOF for each $\mathrm{d}$. The $25-\mathrm{cm}$ counters are used because $\phi$ position is not critical. A monitor is placed in the incident beam $2 \mathrm{~m}$ behind the sample.

The counters are hooked to a common preamplifier and TOF data is recorded. This provides a powder sample diffraction instrument that could prove to be a quality research and analytical diffractometer.

\section{B. Small Angle Scattering}

Next, the small angle flight path is rotated to zero degrees. Slits at the moderator and sample are narrowed and the $25-\mathrm{cm}$ counters are replaced with $10-\mathrm{cm}$ detectors, each connected to a separate timing channel. This allow's observation of larger plane spacings ( $d<200 \mathrm{~A}$ ). This could be a useful analytical instrument.

\section{Single Crystal Laus}

To demonstrate the TOF Laué method, the small angle flight path is rotated back to some finite angle I and a single crystal sample is placed at the sample position. One or more detectors observe Bragg peaks and sort the orders. Without a better detector to cover more space while still being time sensitive, this arrangement can only be $a$ demonstration.

\section{Small $x$}

Turning now to inelastic scattering, Fig. 16 shows an arrangement of the MTR equipment. For a small a measurement, with the longer flight path, rotate the small angle flight path to $0^{\circ}$. Insert the $25 \cdot \mathrm{cm}$ detectors and connect them in common to a time channel. Insert a Fermi chopper in front of the sam. ple and phase it with LAMPF. The equipment is ready for molecular apectra measurements. A long Night path is needed to compensate for the large burst at the moderatos.
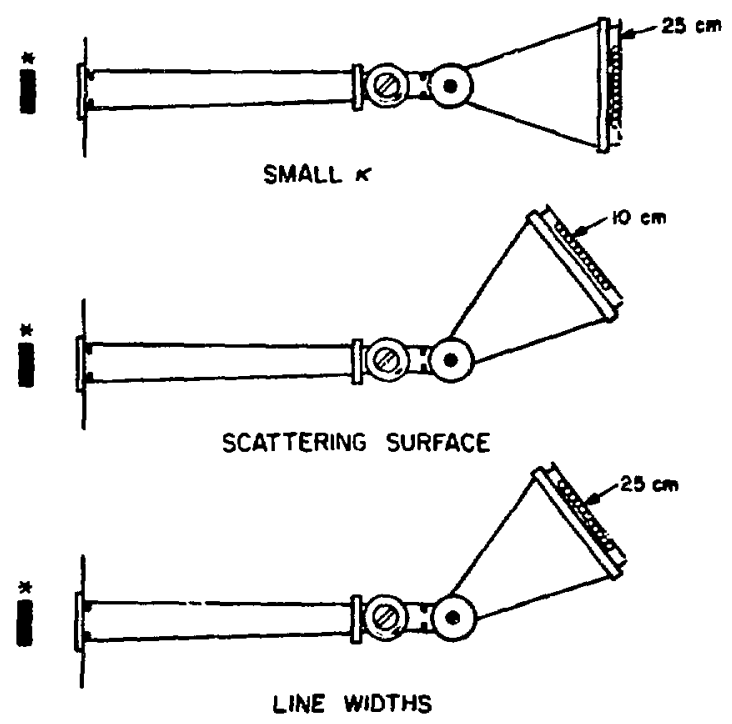

Fig. 16.

$M T R$ equipmeni arranged for neutron inelastic scattering measurements.

\section{E. Scattering Surface}

To demonstrate the scattering surface method, insert the $10-\mathrm{cm}$ detectors in the small angle flight path and connect each to a time channel. Place a single crystal sample at the sample position. To straddle a $\vec{q}$ direction, orient the sample, rotate the flight path, and set $E_{0}$ by udjusting the phase of the Fermi chopper. Phonons across the desired $\vec{q}$ can then be measured. This may well constitute an analytical instrument without further modification.

\section{F. Line Widths}

To measure quasi-elastic line widths or line widths of phonons, replace the $10-\mathrm{cm}$ counters in the arrangement of the preceding paragraph with $25-\mathrm{cm}$ detectors. The sample to be measured is placed at the sample position and the chopper phase set to deliver the desired $E_{0}$. This equipment can only observe meV' of width and not $\mu \mathrm{eV}$.

\section{xII. CONClusions}

Six promising classes of experiments in slow neutron scattering have been presented for WNR 
research. Lattice and space groups of crystalline samples can be determined by a high resolution, powder diffraction instrument. Large distance ordering in polymers, biological samples, and radiationdamaged samples can be measured with the smail angle stattering instrument. 'The $x$-ray Laue method can be improved by the single crystal neutron TOF Laué method.

Molecular spectra will be measured for highly symmetric molecules by the small $k$ method. The constant $\mathbf{Q}$ method that has proven so powerful on steady state reactors will be supplemented in the WNR by the scattering surface method. Diffusive and anharmonic motions in materials will be observed in line-width measurements.

The experimental instruments shouid be built as modules to allow interchar:ge of components. Special effort must go into development of choppers and S.T sensitive detecturs. Each proposed experiment can be initiated with the MTR instruments procured by WNR.

\section{ACKNOWLEDGMENTS}

The author wishes to thank M. S. Moore, R. G. Fluharty, and G. J. Russell for helpful discussions during the period this report was drafted.

\section{REFERENCES}

1. A. Larose and J. Vanderval, Bibliography of Papers Relevant to the Scattering of Thermal Neutrons, 1963-1972 (McMaster University Press, Hamilton, Ontario, 1973).

2. A. Guinier, "Crystallography and the Future," Phys. Today 28, 23 (February 1975).

3. B. P. Schoenborn, Proc. Brookhaven National Laboratory Conf. on "Neutron Scattering and Biology," June i975, to be published.

4. G. Shirane, "Neutron Scatt cring Studies of Structural Phase Transitions at Brookhaven," Rev. Mod. Phys. 46, 437 (1974).

5. National Science Foundation Symposium on "Neutron Scattering in Chemistry," Massachusetts Institute of Technology, Boston, MA, May 26-28, 1975.

6. Workshop on "Uses of Advanced Pulsed Neutron Sources," Argonne National Laboratory, October 20-24, 1975. J. M. Carpenter et al.,
"Neutron Diffraction Measurements on Powder Samples Using ZING-P Pulsed Neutron Source at Argonne," Conf. on Neutron Diffraction, Pettin, Netherlands, August 5.6, 1975, RCN-244 (Octorer 1975). J. M. Carpenter and D. L. Price, "An Intense Pulsed Neutron Source for Argonne National Laboratory," Conf. on Paticle Accelerators, Washington, D. C., March 12-24, 1975.

7. R. M. Brugger, "An Evaluation of Fusion Reactors as Sources of Thermal Neutrons for Seattering Experiments," Physics Dept. Colloquium, Univ. of Missouri, Columbia, February 26, 1975.

8. E. Steichele and P. Arnold, "A High Resolution Neution Time of Flight Diffractometer," Phys. Lett. 44A, 165 (1973).

9. C. Greaves, A. J. Jacobson, B. C. Tofield, and B. E. F. Fender, "A Powder Neutron Diffraction Investigation of the Nuclear and Magnetic Structure of $\mathrm{Sr}_{2} \mathrm{Fe}_{2} \mathrm{O}_{5}$," Acta Crystallogr. B31, 641 (1975).

10. R. M. Brugger, R. B. Bennion, and T. G. Worlton, "The Crystal Structure of Bismuth-11 at 26 kbar," Phys. Lett. 24A, 714 (1967).

11. P. Aldebert, J.-M. Badié, J.-P. Traverse, J.-L. Buevoz, and G. Roult, "Application of a High Temperature Neutron Diffraction Device to the Study of Refactory Oxides," Rev. Ini. Hautes Temp. Refract. 12, 197 (1975).

12. H. Huthmann and G. Inden, "High Temperature Neutron Diffraction on FeTi and CoTi," Phys. Status Solidi 28, K129 (1975).

13. G. Zaccai, J. K. Blasie, B. P. Schoenborn, "Neutron Diffraction Studies of the Location of Water in Lecithin Bilayer Model Membranes," Proc. Nat. Acad. Sci. USA 72, 376 (1975).

14. B. P. Schoenborn and A. C. Nunes, "Neutron Scattering," in Annual Review of Biophysics and Bioengineering, Vol. 1, M. F. Morales, Ed. (Annual Reviews, Inc., Falo Alto, CA), p. 529ff.

15. R. B. Von Dreele, L. Eyring, A. L. Bowman, and J. L. Yarnell, "Refinement of the Crystal Structure of $\mathrm{Pr}_{7} \mathrm{O}_{12}$ by Powder Neutron Diffraction," Acta. Cryst. B31, 971 (1975).

16. G. Bauer and E. Seitz, "Elastic Diffuse Scattering of Neutrons as a Tool for Investigation of Non-Magnetic Point Defects," J. Appl. Crystallogr. 8, 162 (1975). 
17. R. W. Hendricks and J. Schelten, "Measurement of Relative Void Surface Energies in Irradiated Mitals by Small-Angle Scattering," J. Appl. Crystallogr. 8, 193 (1975).

18. W. Schmatz, T. Springer, J. Schelten, and K. Ibel, "Neutron Small-Angle Scattering: Experimental Techniques and Applications," J. Appl. Crystallogr. 7, 96 (1974).

19. J. Schelten, G. D. Wignall, D. G. H. Ballard, and W. Schmatz, "Neutron Small-Angle Scattering by Mixtures of $\mathrm{H}$ and D-tagged Molecules of Polygtyrene and Polyethylene," Colloid Polym. Sci. 252, 749 (1974).

20. G. Lieser, E. W. Fischer, and K. Ibel, "Conformation of Polyethylene Molecules in the Melt as Revealed by Small-Angle Neutron Scattering," J. Polym. Sci., Polym. Lett. Ed. 13, 39 (1975).

21. H. A. Mook, "Neutron Small-Angle Scattering Investigation of "oi. is in Irradiated Materials," J. Appl. Phys. 45, 43 (1974).

22. M. Moan, C. Wolff, and R. Ober, "Study of the Conformation of Polyelectrolytes in Dilute Solutions by Elastic Neutron Scattering," Chem. Phys. Lett. 28, 505 (1974).

23. P. Chieux, "Small Angle Neutron Scatering Studies of Concentration Fluctuations in the Non Metal to Metal Transition Range: Solutions of $7 \mathrm{Li}$ in $\mathrm{ND}_{3}$," Phys. Lett. 48A, 493 (1974).

24. J. Schelten, G. D. Wignall, and D. G. H. Ballard, "Chain Conformation in Molten Polyethylene by Low Angle Neutron Scattering," Polym. Lett. 15, 682 (1974).

25. W. Schmatz, P. H. Dederichs, and H. Scheuer, "Theory of Nuclear and Magnetic Neutron Small Angle Scattering at Dislocations in Anisotropic Cubic Crystals," Z. Phys. 270, 337 (1974).

26. A. C. Nunes, "A Focussing Low-Angle Neutron Diffractometer," Nucl. Instrum. Methods 119, 291 (1974).

27. A. C. Nunes, "The Neutron Fourier Chopper in Protein Crystallography," J. Appl. Crystallogr. \&, 20 (1975).

28. I. Bernal and S. F. Walkins, "Direct Phase Determination from Neutron Diffraction Data of the Structure of Melampodin," Science 178, 1282 (1972).
29. G. P. Felcher and S. W. Peterson, "Schwinger and Anamalous Scattering of Neutrons from CdS," Acta Crystallogr. A31, 76 (1975).

30. B. Hudson, A. Warshel, and R. G. Gordon, "Molecular Inelastic Neutron Scattering. Computational Methods Using Consistent Force Fields," J. Chem. Phys. 61, 2929 (1974).

31. R. E. Schmunk and R. M. Brugger, "The Scattering Surface Method of Measuring Dispersion Relations with a Phased Chopper Velocity Selector," Nucl. Instrum. Methods 12, 365 (1961).

32. H. J. Prask, S. F. Trevino, and J. J. Rush, "Quasielastic Neutron Scattering Study of Ammonium-Ion Reorientations in Ammonium Perchlorate," J. Chem. Phys. 62, 4156 (1975).

33. B. Cvikl, M. Čopič, V. Dimic, J. W. Doene, and W. Franklin, "Molecular Translation-Rotational Coupling Contribution to Neutron Incident Line Broadening in Nematic Liquid Crystals," J. Phys. (Paris) 36, 441 (1975).

34. G. Allen, "Neutron Scattering Studies of Self Diffusion in Rubbers and Polymer Melts," Pure Appl. Chem. 39, 151 (1974).

35. H. Hervet, F. Volino, A. J. Dianoux, and R. E. Lechner, "Nature of the Molecular Alignment in a Smectic-H Phase," Phys. Rev. Lett. 34, 451 (1975).

36. G. Allen, R. E. Ghosh, A. Heidemann, J. S. Hliggins, and W. S. Howells, "On the Structure of the Quasielas $₫$ ic Incoherent Neutron Scattering from Poly(Dimethyl-Siloxane)," Chem. Phys. Lett. 27, 308 (1974).

37. R. Pynn and J. D. Axe, “A Neutron Measurement of the Effect of a Magnetic Field on Phonon Lifetimes in Niobium," J. Phys. F 4,1898 (1974).

38. M. Birr. A. Heidemann, and B. Alefeld, "A Neutron Crystal Spectrometer with Extremely High Energy Tlesolution," Nucl. Instrum. Methoós 95, 435 (i971).

39. R. Allemand, J. Bourdel, E. Roudant, P. Convert, K. Ibel, J. Jacobe, J. P. Cotton, and F. Farnoux, "Position-Sensitive Detectors (P.S.D.) for Neutron Diffraction," Nucl. Instrum. Methods 126, 29 (1975). 